\title{
On Line Tuning Premise and Consequence FIS Based on Lyaponuv Theory with Application to Continuum Robot
}

\author{
Narges Gholami Mozafari, Farzin Piltan, Mohammad Shamsodini, Azita Yazdanpanah, Ali Roshanzamir \\ Laboratory of Robotics and Control Automation, Institute of Advance Science and Technology -SSP, Shiraz, Iran \\ E-mail: Piltan_f@iranssp.com,http://www.iranssp.com
}

\begin{abstract}
Classical sliding mode controller is robust to model uncertainties and external disturbances. A sliding mode control method with a switching control low guarantees asymptotic stability of the system, but the addition of the switching control law introduces chattering in to the system. One way of attenuating chattering is to insert a saturation function inside of a boundary layer around the sliding surface. Unfortunately, this addition disrupts Lyapunov stability of the closed-loop system. Classical sliding mode control method has difficulty in handling unstructured model uncertainties. One can overcome this problem by combining a sliding mode controller and fuzzy system together. Fuzzy rules allow fuzzy systems to approximate arbitrary continuous functions. To approximate a time-varying nonlinear system, a fuzzy system requires a large amount of fuzzy rules. This large number of fuzzy rules will cause a high computation load. The addition of an adaptive law to a fuzzy sliding mode controller to online tune the parameters of the fuzzy rules in use will ensure a moderate computational load. Refer to this research; tuning methodology can online adjust both the premise and the consequence parts of the fuzzy rules. Since this algorithm for is specifically applied to a robot manipulator.
\end{abstract}

Index Terms - Classical Sliding Mode Controller, Robust, Uncertainties, Chattering Phenomenon, Lyapunov Theory, Fuzzy Sliding Mode Controller, Tuning Fuzzy Sliding Mode Controller, Robotic System

\section{Introduction}

Sliding mode controller (SMC) is one of the influential nonlinear controllers in certain and uncertain systems which are used to present a methodical solution for two main important controllers' challenges, which named: stability and robustness. Conversely, this controller is used in different applications; sliding mode controller has consequent disadvantages ; chattering phenomenon and nonlinear equivalent dynamic formulation; which chattering is caused to some difficulties such as saturation and heat for mechanical parts of robot manipulators or drivers and nonlinear equivalent dynamic formulation in uncertain systems is most important challenge in highly nonlinear uncertain system[1, 5-29]. In order to solve the chattering in the systems output, boundary layer method should be applied so beginning able to recommended model in the main motivation which in this method the basic idea is replace the discontinuous method by saturation (linear) method with small neighbourhood of the switching surface. To remove the above setbacks, control researchers have applied artificial intelligence method (e.g., fuzzy logic, neural network and genetic algorith m) in nonlinear robust controller (e.g., sliding mode controller, backstepping and feedback linearization) besides this technique is very useful in order to implement easily. Estimated uncertainty method is used in term of uncertainty estimator to compensation of the system uncertainties. It has been used to solve the chattering phenomenon and also nonlinear equivalent dynamic. If estimator has an acceptable performance to compensate the uncertainties, the chattering is reduced. Research on estimated uncertainty to reduce the chattering is significantly growing as their applications such as industrial automation and continuum robot manipulator. In recent years, artificial intelligence theory has been used in sliding mode control systems [31-40, 68]. Neural network, fuzzy logic and neurofuzzy are synergically combined with nonlinear classical controller and used in nonlinear, time variant and uncertainty plant (e.g., robot manipulator). Fuzzy logic controller (FLC) is one of the most important applications of fuzzy logic theory. This controller can be used to control nonlinear, uncertain and noisy systems. This method is free of some model-based techniques as in classical controllers [33-38]. The main reasons to use fuzzy logic technology are able to give approximate recommended solution for uncertain and complex systems to easy understanding and flexible. Fuzzy logic provides a method which is able to model a controller for nonlinear plant with a set of IF-THEN rules, or it can identify the control actions and describe them by using fuzzy rules. The applications of artificial intelligence, neural networks and fuzzy logic, on robot arm control have reported in [29-31]. In various dynamic parameters systems that need to be training on- 
line tuneable gain control methodology is used. On-line tuneable control methodology can be classified into two main groups, namely, traditional adaptive method and fuzzy adaptive method. Fuzzy adaptive method is used in systems which want to training parameters by expert knowledge. Traditional adaptive method is used in systems which some dynamic parameters are known. In this research in order to solve disturbance rejection and uncertainty dynamic parameter, on-line tuneable method is applied to artificial sliding mode controller.

Continuum robot manipulator is collection of links that connect to each other by joints, these joints can be revolute and prismatic that revolute joint has rotary motion around an axis and prismatic joint has linear motion around an axis. Each joint provides one or more degrees of freedom (DOF). From the mechanical point of view, continuum robot manipulator is divided into two main groups, which called; serial robot links and parallel robot links. In serial continuum robot manipulator, links and joints is serially connected between base and final frame (end-effector). Parallel continuum robot manipulators have many legs with some links and jo ints, where in these robot manipulators base frame has connected to the final frame. Most of continuum robots are serial links, which in serial robot manipulator the axis of the first three joints has a known as major axis, these axes show the position of endeffector, the axis number four to six are the minor axes that use to calculate the orientation of end-effector, at last the axis number seven to $\boldsymbol{n}$ use to avoid the bad situation. Kinematics is an important subject to find the relationship between rigid bodies (e.g., position and orientation) and end-effector in robot manipulator. The mentioned topic is very important to describe the three areas in continuum robot manipulator: practical application, dynamic part, and control purposed therefore kinematics play important role to design accurate controller for robot manipulators. Continuum robot manipulator kinematics is divided into two main groups: forward kinematics and inverse kinematics where forward kinematics is used to calculate the position and orientation of end-effector with given joint parameters (e.g., joint angles and joint displacement) and the activated position and orientation of endeffector calculate the joint variables in Inverse Kinematics[1]. Dynamic modeling of robot manipulators is used to describe the behavior of robot manipulator, design of model based controller, and for simulation. The dynamic modeling describes the relationship between joint motion, velocity, and accelerations to force/torque or current/voltage and also it can be used to describe the particular dynamic effects (e.g., inertia, coriolios, centrifugal, and the other parameters) to behavior of system[1]. The OCTARM continuum robot serially links robot manipulator has a nonlinear and uncertain dynamic parameters serial link 6 degrees of freedom (DOF) continuum robot manipulator.
Even though, sliding mode controller is used in wide range areas but, pure it has chattering problem and nonlinear dynamic part challenges. On the other hand, fuzzy logic controller has been used for nonlinear and uncertain systems controlling. Conversely pure fuzzy logic controller (FLC) works in many areas, it cannot guarantee the basic requirement of stability and acceptable performance. Although both SMC and FLC have been applied successfully in many applications but they have some limitations. The boundary layer method is used to reduce or eliminate the chattering and proposed fuzzy Lyapunov estimator method focuses on substitution fuzzy logic system instead of dynamic nonlinear equation to implement easily and avoid mathematical model base controller. To reduce the effect of uncertainty in proposed method, novel antecedent and consequent adaptive method is applied to fuzzy sliding mode controller in robot manipulator. The main goal is to design a novel fuzzy adaptive fuzzy estimation sliding mode methodology which applied to robot manipulator with easy to design and implement. Robot manipulator has nonlinear dynamic and uncertain parameters consequently; following objectives have been pursuit in the mentioned research: To develop a chattering in a position pure variable structure controller against uncertainties, to design and implement a Lyapunov fuzzy structure variable controller in order to solve the equivalent problems with minimum rule base and finally to develop a position fuzzy (antecedent and consequent) adaptive fuzzy estimation sliding mode controller in order to solve the disturbance rejection and reduce the computation load.

This paper is organized as follows:

In section 2, detail of dynamic equation of continuum robot arm, introduced the sliding mode controller and fuzzy logic theory are presented. Detail of tuning methodology which online adjusted both the premise and the consequence parts of the fuzzy rules is presented in section 3 . In section 4, the simulation result is presented and finally in section 5 , the conclusion is presented.

\section{Theory}

Dynamic Modeling of Continuum Robot: The Continuum section analytical model developed here consists of three modules stacked together in series. In general, the model will be a more precise replication of the behavior of a continuum arm with a greater of modules included in series. However, we will show that three modules effectively represent the dynamic behavior of the hardware, so more complex models are not motivated. Thus, the constant curvature bend exhibited by the section is incorporated inherently within the model. The model resulting from the application of Lagrange's equations of motion obtained for this system can be represented in the form 


$$
F_{\text {coeff }} \underline{\tau}=D(\underline{q}) \underline{\ddot{q}}+C(\underline{q}) \underline{\dot{q}}+G(\underline{q})
$$

where $\tau$ is a vector of input forces and $q$ is a vector of generalized co-ordinates. The force coefficient matrix $F_{\text {coeff }}$ transforms the input forces to the generalized forces and torques in the system. The inertia matrix, $D$ is composed of four block matrices. The block matrices that correspond to pure linear accelerations and pure angular accelerations in the system (on the top left and on the bottom right) are symmetric. The matrix $C$ contains coefficients of the first order derivatives of the generalized co-ordinates. Since the system is nonlinear, many elements of $C$ contain first order derivatives of the generalized co-ordinates. The remaining terms in the dynamic equations resulting from gravitational potential energies and spring energies are collected in the matrix $G$. The coefficient matrices of the dynamic equations are given below,

$$
\begin{aligned}
& \text { Fcoeff }= \\
& {\left[\begin{array}{cccccc}
1 & 1 & \cos \left(\theta_{1}\right) & \cos \left(\theta_{1}\right) & \cos \left(\theta_{1}+\theta_{2}\right) & \cos \left(\theta_{1}+\theta_{2}\right) \\
0 & 0 & 1 & 1 & \cos \left(\theta_{2}\right) & \cos \left(\theta_{2}\right) \\
0 & 0 & 0 & 0 & 1 & 1 \\
1 / 2 & -1 / 2 & 1 / 2 & -1 / 2 & 1 / 2+s_{2} \sin \left(\theta_{2}\right) & -1 / 2+s_{2} \sin \left(\theta_{2}\right) \\
0 & 0 & 1 / 2 & -1 / 2 & 1 / 2 & -1 / 2 \\
0 & 0 & 0 & 0 & 1 / 2 & -1 / 2
\end{array}\right]} \\
& D(\underline{q})=
\end{aligned}
$$

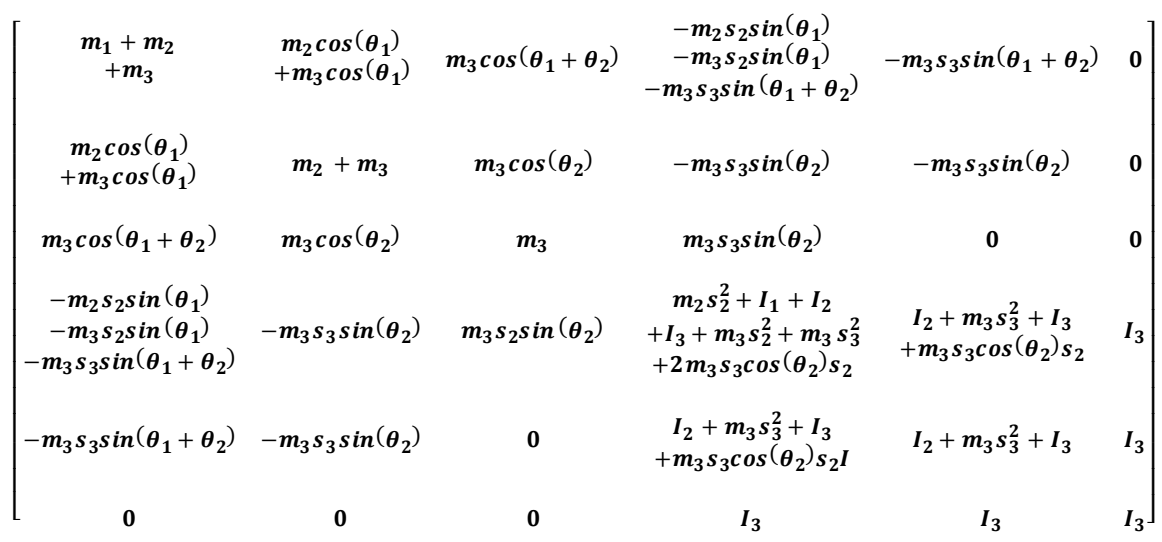

$$
\begin{aligned}
& C(\underline{q})=
\end{aligned}
$$

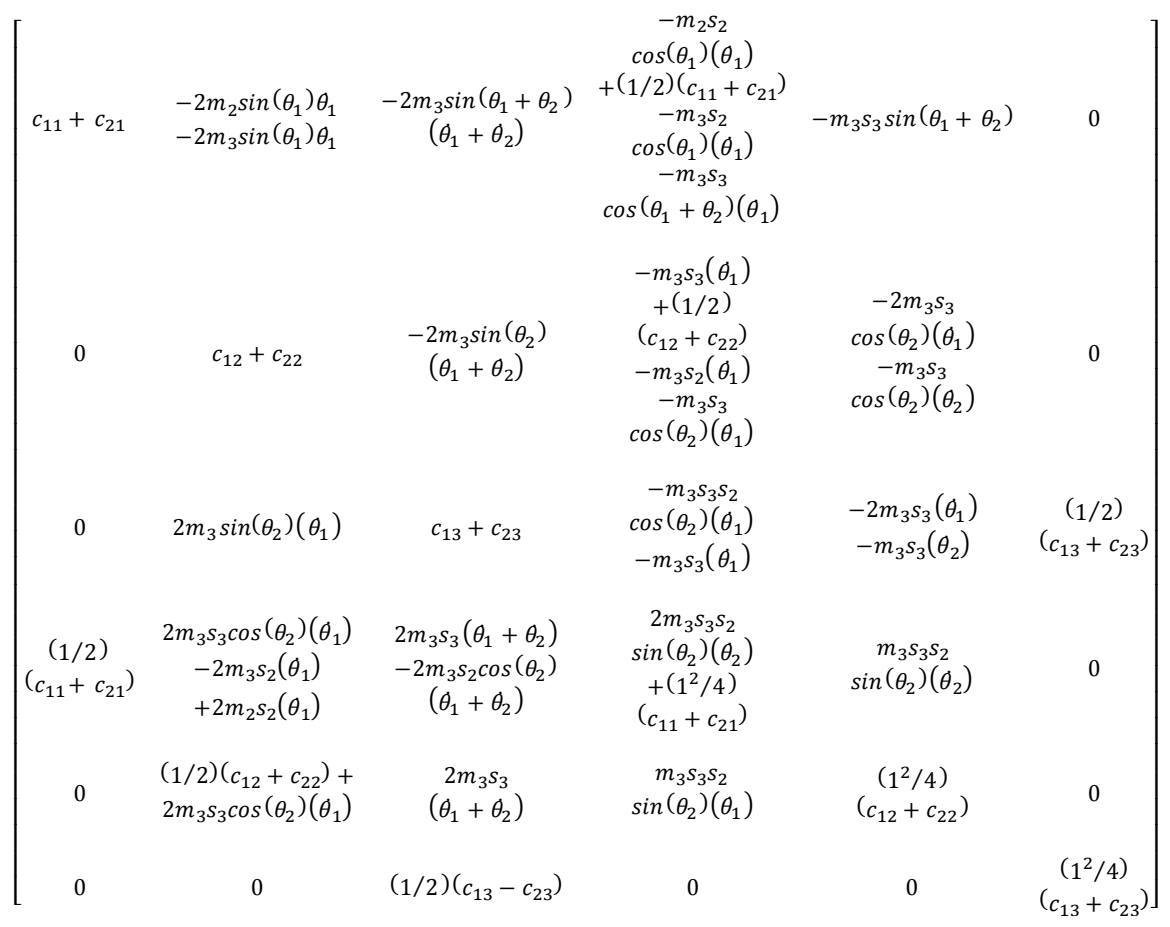




$$
\boldsymbol{G}(\underline{\boldsymbol{q}})=\left[\begin{array}{c}
-m_{1} g-m_{2} g+k_{11}\left(s_{1}+(1 / 2) \theta_{1}-s_{01}\right)+k_{21}\left(s_{1}-(1 / 2) \theta_{1}-s_{01}\right)-m_{3} g \\
-m_{2} g \cos \left(\theta_{1}\right)+k_{12}\left(s_{2}+(1 / 2) \theta_{2}-s_{02}\right)+k_{22}\left(s_{2}-(1 / 2) \theta_{2}-s_{02}\right)-m_{3} g \cos \left(\theta_{1}\right) \\
-m_{3} g \cos \left(\theta_{1}+\theta_{2}\right)+k_{13}\left(s_{3}+(1 / 2) \theta_{3}-s_{03}\right)+k_{23}\left(s_{3}-(1 / 2) \theta_{3}-s_{03}\right) \\
m_{2} s_{2} g \sin \left(\theta_{1}\right)+m_{3} s_{3} g \sin \left(\theta_{1}+\theta_{2}\right)+m_{3} s_{2} g \sin \left(\theta_{1}\right)+k_{11}\left(s_{1}+(1 / 2) \theta_{1}-s_{01}\right)(1 / 2) \\
+k_{21}\left(s_{1}-(1 / 2) \theta_{1}-s_{01}\right)(-1 / 2) \\
m_{3} s_{3} g \sin \left(\theta_{1}+\theta_{2}\right)+k_{12}\left(s_{2}+(1 / 2) \theta_{2}-s_{02}\right)(1 / 2)+k_{22}\left(s_{2}-(1 / 2) \theta_{2}-s_{02}\right)(-1 / 2) \\
k_{13}\left(s_{3}+(1 / 2) \theta_{3}-s_{03}\right)(1 / 2)+k_{23}\left(s_{3}-(1 / 2) \theta_{3}-s_{03}\right)(-1 / 2)
\end{array}\right]
$$

$$
s(x, t)=\left(\frac{d}{d t}+\lambda\right)^{n-1} \tilde{x}=0
$$
nonlinear controller which has been analyzed by many researchers especially in recent years. This theory was first proposed in the early 1950 by Emelyanov and several co-workers and has been extensively developed since then with the invention of high speed control devices [2]. The main reason to opt for this controller is its acceptable control performance in wide range and solves two most important challenging topics in control which names, stability and robustness [7, 17-20]. Sliding mode control theory for control of robot manipulator was first proposed in 1978 by Young to solve the set point problem $\left(\dot{\boldsymbol{q}}_{\boldsymbol{d}}=\mathbf{0}\right)$ by discontinuous method in the following form [19, 3];

$$
\tau_{(q, t)}= \begin{cases}\tau_{i}^{+}(q, t) & \text { if } S_{i}>0 \\ \tau_{i}^{-}(q, t) & \text { if } S_{i}<0\end{cases}
$$

where $\boldsymbol{S}_{\boldsymbol{i}}$ is sliding surface (switching surface), $\boldsymbol{i}=\mathbf{1}, \mathbf{2}, \ldots \ldots, \boldsymbol{n}$ for $n$-DOF robot manipulator, $\boldsymbol{\tau}_{\boldsymbol{i}}(\boldsymbol{q}, \boldsymbol{t})$ is the $\boldsymbol{i}^{\boldsymbol{t h}}$ torque of joint. Sliding mode controller is divided into two main sub controllers: discontinues controller $\left(\boldsymbol{\tau}_{\text {dis }}\right)$ and equivalent controller $\left(\boldsymbol{\tau}_{\boldsymbol{e q}}\right)$.

Robot manipulators are one of the highly nonlinear and uncertain systems which caused to needed to robust controller. This section provides introducing the formulation of sliding mode controller to robot manipulator based on $[1,6]$ Consider a nonlinear single input dynamic systemof the form [6]:

$$
x^{(n)}=f(\vec{x})+b(\vec{x}) u
$$

Where $\mathrm{u}$ is the vector of control input, $\boldsymbol{x}^{(\boldsymbol{n})}$ is the $\boldsymbol{n}^{\boldsymbol{t h}}$ derivation of $x, x=\left[x, \dot{x}, \ddot{x}, \ldots, x^{(n-1)}\right]^{T}$ is the state vector, $\boldsymbol{f}(\boldsymbol{x})$ is unknown or uncertainty, and $\boldsymbol{b}(\boldsymbol{x})$ is of known sign function. The control problem is truck to the desired state; $\boldsymbol{x}_{\boldsymbol{d}}=\left[\boldsymbol{x}_{d}, \dot{\boldsymbol{x}}_{d}, \ddot{\boldsymbol{x}}_{\boldsymbol{d}}, \ldots, \boldsymbol{x}_{\boldsymbol{d}}{ }^{(\boldsymbol{n}-1)}\right]^{T}$, and have an acceptable error which is given by:

$$
\tilde{x}=x-x_{d}=\left[\widetilde{x}, \ldots, \widetilde{x}^{(n-1)}\right]^{T}
$$

A time-varying sliding surface $\boldsymbol{s}(\boldsymbol{x}, \boldsymbol{t})$ is given by the following equation: where $\lambda$ is the positive constant. To further penalize tracking error integral part can be used in sliding surface part as follows:

$$
s(x, t)=\left(\frac{d}{d t}+\lambda\right)^{n-1}\left(\int_{0}^{t} \tilde{x} \boldsymbol{d t}\right)=\mathbf{0}
$$

The main target in this methodology is kept the sliding surface slope $\boldsymbol{s}(\boldsymbol{x}, \boldsymbol{t})$ near to the zero. Therefore, one of the common strategies is to find input $\boldsymbol{U}$ outside of $\boldsymbol{s}(\boldsymbol{x}, \boldsymbol{t})$.

$$
\frac{1}{2} \frac{d}{d t} s^{2}(x, t) \leq-\zeta|s(x, t)|
$$

where $\zeta$ is positive constant and in equation (11) forces tracking trajectories is towards sliding condition.

$$
\text { If } \mathbf{S}(\mathbf{0})>\mathbf{0} \rightarrow \frac{\mathrm{d}}{\mathrm{dt}} \mathbf{S}(\mathbf{t}) \leq-\zeta
$$

To eliminate the derivative term, it is used an integral term from $\mathrm{t}=0$ to $\mathrm{t}=\boldsymbol{t}_{\text {reach }}$

$$
\begin{aligned}
& \int_{t=0}^{t=t_{\text {reach }}} \frac{d}{d t} S(t) \leq-\int_{t=0}^{t=t_{\text {reach }}} \eta \rightarrow \\
& S\left(t_{\text {reach }}\right)^{-S(0)} \leq-\zeta\left(t_{\text {reach }}-0\right)
\end{aligned}
$$

Where $t_{\text {reach }}$ is the time that trajectories reach to the sliding surface so, suppose $S\left(t_{\text {reach }}=0\right)$ defined as

$$
0-S(0) \leq-\eta\left(t_{\text {reach }}\right) \rightarrow t_{\text {reach }} \leq \frac{S(0)}{\zeta}
$$

and

$$
\begin{aligned}
& \text { if } S(0)<0 \rightarrow 0-S(0) \leq-\eta\left(t_{\text {reach }}\right) \rightarrow \\
& S(0) \leq-\zeta\left(t_{\text {reach }}\right) \rightarrow t_{\text {reach }} \leq \frac{|S(0)|}{\eta}
\end{aligned}
$$


Equation (15) guarantees time to reach the sliding surface is smaller than $\frac{|\boldsymbol{S}(\mathbf{0})|}{\zeta}$ since the trajectories are outside of $S(t)$.

$$
\text { if } S_{t_{\text {reach }}}=S(0) \rightarrow \operatorname{error}\left(x-x_{d}\right)=0
$$

suppose $\mathrm{S}$ is defined as

$$
\begin{aligned}
s(x, t)=\left(\frac{d}{d t}+\lambda\right) & \tilde{x} \\
= & \left(\dot{x}-\dot{\mathbf{x}}_{d}\right)+\lambda\left(\mathbf{x}-\mathbf{x}_{\mathrm{d}}\right)
\end{aligned}
$$

The derivation of $\mathrm{S}$, namely, $\dot{S}$ can be calculated as the following;

$$
\dot{\boldsymbol{S}}=\left(\ddot{\mathbf{x}}-\ddot{\mathbf{x}}_{\mathbf{d}}\right)+\lambda\left(\dot{\mathbf{x}}-\dot{\mathbf{x}}_{\mathbf{d}}\right)
$$

suppose the second order systemis defined as;

$$
\begin{aligned}
& \ddot{x}=f+u \\
& \lambda\left(\dot{\mathbf{x}}-\dot{\mathbf{x}}_{\mathrm{d}}\right)
\end{aligned} \rightarrow \dot{S}=\boldsymbol{f}+\boldsymbol{U}-\ddot{x}_{d}+
$$

Where $\boldsymbol{f}$ is the dynamic uncertain, and also since $S=0$ and $\dot{S}=0$, to have the best approximation , $\widehat{\boldsymbol{U}}$ is defined as

$$
\widehat{U}=-\widehat{f}+\ddot{x}_{d}-\lambda\left(\dot{\mathbf{x}}-\dot{\mathbf{x}}_{\mathbf{d}}\right)
$$

A simple solution to get the sliding condition when the dynamic parameters have uncertainty is the switching control law:

$$
U_{d i s}=\widehat{U}-K(\vec{x}, t) \cdot \operatorname{sgn}(s)
$$

where the switching function $\operatorname{sgn}(\mathbf{S})$ is defined as

$$
\operatorname{sgn}(s)= \begin{cases}1 & s>0 \\ -1 & s<0 \\ 0 & s=0\end{cases}
$$

and the $\boldsymbol{K}(\overrightarrow{\boldsymbol{x}}, \boldsymbol{t})$ is the positive constant. Suppose by (21) the following equation can be written as,

$$
\begin{aligned}
& \frac{1}{2} \frac{d}{d t} S^{2}(x, t)=S \cdot S=[f-\hat{f}-K \operatorname{sgn}(s)] \\
& S=(f-\widehat{f}) \cdot S-K|S|
\end{aligned}
$$

and if the equation (22) instead of (23) the sliding surface can be calculated as

$$
\begin{aligned}
& s(x, t)=\left(\frac{d}{d t}+\lambda\right)^{2}\left(\int_{0}^{t} \tilde{x} d t\right)=\left(\dot{\mathbf{x}}-\dot{\mathbf{x}}_{\mathrm{d}}\right)+ \\
& 2 \lambda\left(\dot{\mathbf{x}}-\dot{\mathbf{x}}_{\mathrm{d}}\right)-\lambda^{2}\left(\mathbf{x}-\mathbf{x}_{\mathrm{d}}\right)
\end{aligned}
$$

in this method the approximation of $\boldsymbol{U}$ is computed as

$$
\widehat{U}=-\widehat{f}+\ddot{x}_{d}-2 \lambda\left(\dot{\mathbf{x}}-\dot{\mathbf{x}}_{\mathbf{d}}\right)+\lambda^{2}\left(\mathbf{x}-\mathbf{x}_{\mathbf{d}}\right)
$$

Therefore the switching function $\operatorname{sgn}(\mathbf{S})$ is added to the control law as

$$
U=K(\vec{x}, t) \cdot \operatorname{Sgn}(S)
$$

Based on above discussion, the control law for a multi degrees of freedom robot manipulator is written as:

$$
\tau=\tau_{e q}+\tau_{d i s}
$$

Where, the model-based component $\boldsymbol{\tau}_{\boldsymbol{e q}}$ is the nominal dynamics of systems and $\boldsymbol{\tau}_{\boldsymbol{e q}}$ can be calculate as follows:

$$
\tau_{e q}=\left[D^{-1}(f+C+G)+\dot{S}\right] D
$$

and $\boldsymbol{\tau}_{\boldsymbol{d i s}}$ is computed as;

$$
\tau_{d i s}=K \cdot \operatorname{Sgn}(S)
$$

The control output can be written as;

$$
\tau=\tau_{e q}+K \cdot \operatorname{Sgn}(S)
$$

By (29) and (30) the sliding mode control of robot manipulator is calculated as;

$$
\tau=\left[D^{-1}(f+C+G)+\dot{S}\right] D+K \cdot \operatorname{Sgn}(S)
$$

The Lyapunov formulation can be written as follows,

$$
V=\frac{1}{2} S^{T} . D . S
$$

The derivation of $V$ can be determined as,

$$
\dot{V}=\frac{1}{2} S^{T} \cdot \dot{D} \cdot S+S^{T} D \dot{S}
$$

The dynamic equation of robot manipulator can be written based on the sliding surface as

$$
D \dot{S}=-V S+D \dot{S}+V S+G-\tau
$$

it is assumed that

$$
S^{T}(\dot{D}-2 V) S=0
$$

by substituting (34) in (33)

$$
\begin{aligned}
& \dot{V}=\frac{1}{2} S^{T} \dot{D} S-S^{T} V S+S^{T}(D \dot{S}+V S+G- \\
& \tau)=S^{T}(D \dot{S}+V S+G-\tau)
\end{aligned}
$$


Suppose the control input is written as follows

$$
\begin{aligned}
& \hat{\boldsymbol{\tau}}=\widehat{\boldsymbol{\tau}_{e q}}+\widehat{\boldsymbol{\tau}_{\text {dis }}}=\left[\widehat{D^{-1}}(\widehat{V}+\widehat{G})+\dot{S}\right] \widehat{D}+ \\
& K \cdot \operatorname{sgn}(S)+K_{v} S
\end{aligned}
$$

By replacing the equation (37) in (36)

$$
\begin{aligned}
& \dot{V}=S^{T}(D \dot{S}+V S+G-\widehat{D} \dot{S}-\widehat{V} S-\widehat{G}- \\
& K_{v} S-K \operatorname{sgn}(S)=S^{T}(\widetilde{D} \dot{S}+\widetilde{V} S+\widetilde{G}- \\
& \left.K_{v} S-K \operatorname{sgn}(S)\right)
\end{aligned}
$$

It is obvious that

$$
\begin{aligned}
& \left|\widetilde{D} \dot{S}+\widetilde{V} S+\widetilde{G}-K_{v} S\right| \leq|\widetilde{D} \dot{S}|+|\widetilde{V} S|+ \\
& |\widetilde{G}|+\left|K_{v} S\right|
\end{aligned}
$$

The Lemma equation in robot manipulator system can be written as follows

$$
K_{u}=\left[|\widetilde{D} \dot{S}|+|V S|+|G|+\left|K_{v} S\right|+\eta\right]_{i}, i
$$

The equation (35) can be written as

$$
K_{u} \geq\left|\left[\widetilde{D} \dot{S}+V S+G-K_{v} S\right]_{i}\right|+\eta_{i}
$$

Therefore, it can be shown that

$$
\dot{V} \leq-\sum_{i=1}^{n} \eta_{i}\left|S_{i}\right|
$$

Consequently the equation (42) guaranties the stability of the Lyapunov equation.

Fuzzy Inference Engine: This section provides a review about foundation of fuzzy logic based on [3253]. Supposed that $U$ is the universe of discourse and $x$ is the ele ment of $U$, therefore, a crisp set can be defined as a set which consis ts of different elements $(x)$ will all or no membership in a set. A fuzzy set is a set that each element has a membership grade, therefore it can be written by the following definition;

$$
A=\left\{x, \mu_{A}(x) \mid x \in X\right\} ; A \in U
$$

Where an element of universe of discourse is $x, \mu_{A}$ is the membership function (MF) of fuzzy set. The membership function $\left(\mu_{A}(x)\right)$ of fuzzy set $A$ must have a value between zero and one. If the membership function $\mu_{A}(x)$ value equal to zero or one, this set change to a crisp set but if it has a value between zero and one, it is a fuzzy set. Defining me mbership function for fuzzy sets has divided into two main groups; namely; numerical and functional method, which in numerical method each number has different degrees of membership function and functional method used standard functions in fuzzy sets. The membership function which is often used in practical applications includes triangular form, trapezoidal form, bell-shaped form, and Gaussian form.

Linguistic variable can open a wide area to use of fuzzy logic theory in many applications (e.g., control and system identification). In a natural artificial language all numbers replaced by words or sentences.

If - then Rule statements are used to formulate the condition statements in fuzzy logic. A single fuzzy If - then rule can be written by

\section{If $x$ is $A$ Then $y$ is $B$}

where $A$ and $B$ are the Linguistic values that can be defined by fuzzy set, the If - part of the part of " $x$ is $A$ " is called the antecedent part and the then part of the part of " $y$ is $B$ " is called the Consequent or Conclusion part. The antecedent of a fuzzy if-then rule can have multiple parts, which the following rules shows the multiple antecedent rules:

$$
\text { if e is NB and } \dot{e} \text { is } M L \text { then } T \text { is } L L
$$

where $e$ is error, $\dot{e}$ is change of error, $N B$ is Negative Big, $M L$ is Medium Left, $T$ is torque and $L L$ is Large Left. If - then rules have three parts, namely, fuzzify inputs, apply fuzzy operator and apply implication method which in fuzzify inputs the fuzzy statements in the antecedent replaced by the degree of membership, apply fuzzy operator used when the antecedent has multiple parts and replaced by single number between 0 to 1 , this part is a degree of support for the fuzzy rule, and apply implication method used in consequent of fuzzy rule to replaced by the degree of membership. The fuzzy inference engine offers a mechanism for transferring the rule base in fuzzy set which it is divided into two most important methods, namely, Mamdani method and Sugeno method. Mamdani method is one of the common fuzzy inference systems and he designed one of the first fuzzy controllers to control of system engine. Mamdani's fuzzy inference system is divided into four major steps: fuzzification, rule evaluation, aggregation of the rule outputs and defuzzification. Michio Sugeno use a singleton as a membership function of the rule consequent part. The following definition shows the Mamdani and Sugeno fuzzy rule base

$$
\begin{array}{ccr}
\text { Mamdani } & \text { F. } R^{1}: \text { if } & x \text { is A and } \\
\text { y is } B \text { then } & z \text { is } C \\
\text { Sugeno } & \text { F. } R^{1}: \text { if } & x \text { is A and } \\
y \text { is } B & \text { then } & f(x, y) \text { is } C
\end{array}
$$

When $x$ and $y$ have crisp values fuzzification calculates the membership degrees for antecedent part. Rule evaluation focuses on fuzzy operation ( $A N D / O R$ ) in the antecedent of the fuzzy rules. The aggregation is 
used to calculate the output fuzzy set and several methodologies can be used in fuzzy logic controller aggregation, namely, Max-Min aggregation, Sum-Min aggregation, Max-bounded product, Max-drastic product, Max-bounded sum, Max-algebraic sum and Min-max. Two most common methods that used in fuzzy logic controllers are Max-min aggregation and Sum-min aggregation. Max-min aggregation defined as below

$$
\begin{aligned}
& \mu_{U}\left(x_{k}, y_{k}, U\right)=\mu_{\cup i=1}^{r} F R^{i}\left(x_{k}, y_{k}, U\right) \\
& =\max \left\{\min _{i=1}^{r}\left[\mu_{R p q}\left(x_{k}, y_{k}\right), \mu_{p_{m}}(U)\right]\right\}
\end{aligned}
$$

The Sum-min aggregation defined as below

$$
\begin{aligned}
& \mu_{U}\left(x_{k}, y_{k}, U\right)=\mu_{\cup \cup_{i=1}^{r} F R^{i}}\left(x_{k}, y_{k}, U\right) \\
& =\sum \min _{i=1}^{r}\left[\mu_{R p q}\left(x_{k}, y_{k}\right), \mu_{p_{m}}(U)\right]
\end{aligned}
$$

where $r$ is the number of fuzzy rules activated by $x_{k}$ and $y_{k}$ and also $\mu_{\cup_{i=1}^{r} F R} i\left(x_{k}, y_{k}, U\right)$ is a fuzzy interpretation of $i-t h$ rule. Defuzzification is the last step in the fuzzy inference system which it is used to transform fuzzy set to crisp set. Consequently defuzzification's input is the aggregate output and the defuzzification's output is a crisp number. Centre of gravity method $(C O G)$ and Centre of area method ( $C O A)$ are two most common defuzzification methods, which COG method used the following equation to calculate the defuzzification

$$
\operatorname{COG}\left(x_{k}, y_{k}\right)=\frac{\sum_{i} U_{i} \sum_{j=1}^{r} \cdot \mu_{u}\left(x_{k}, y_{k}, U_{i}\right)}{\sum_{i} \sum_{j=1}^{r} \cdot \mu_{u}\left(x_{k}, y_{k}, U_{i}\right)}
$$

and $C O A$ method used the following equation to calculate the defuzzification

$$
\operatorname{COA}\left(x_{k}, y_{k}\right)=\frac{\sum_{i} U_{i}, \mu_{u}\left(x_{k}, y_{k}, U_{i}\right)}{\sum_{i} \mu_{U} \cdot\left(x_{k}, y_{k}, U_{i}\right)}
$$

Where $\operatorname{COG}\left(x_{k}, y_{k}\right)$ and $\operatorname{COA}\left(x_{k}, y_{k}\right)$ illustrates the crisp value of defuzzification output, $U_{i} \in U$ is discrete element of an output of the fuzzy set, $\mu_{U} \cdot\left(x_{k}, y_{k}, U_{i}\right)$ is the fuzzy set membership function, and $r$ is the number of fuzzy rules.

Based on foundation of fuzzy logic methodology; fuzzy logic controller has played important rule to design nonlinear controller for nonlinear and uncertain systems [53-66]. However the application area for fu zzy control is really wide, the basic form for all command types of controllers consists of;

- Input fuzzification (binary-to-fuzzy[B/F]conversion)

- Fuzzy rule base (knowledge base)

- Inference engine

- Output defuzzification (fuzzy-tobinary $[\mathrm{F} / \mathrm{B}]$ conversion).

\section{Methodology}

First part is focused on eliminate the oscillation (chattering) in pure SMC based on linear boundary layer method. To reduce or eliminate the chattering it is used the boundary layer method; in boundary layer method the basic idea is replace the discontinuous method by saturation (linear) method with small neighborhood of the switching surface. This replace is caused to increase the error performance [20-24].

$$
B(t)=\{x,|S(t)| \leq \emptyset\} ; \emptyset>0
$$

Where $\emptyset$ is the boundary layer thickness. Therefore, to have a smote control law, the saturation function $\boldsymbol{S a t}(\boldsymbol{S} / \varnothing)$ added to the control law:

$$
U=K(\vec{x}, t) . \operatorname{Sat}(S / \varnothing)
$$

Where $\boldsymbol{S a t}(\boldsymbol{S} / \varnothing)$ can be defined as

$$
\begin{aligned}
& \operatorname{sat}(s / \varnothing) \\
& =\left\{\begin{array}{cc}
1 & (s / \varnothing>1) \\
-1 & (s / \varnothing<1) \\
s / \varnothing & (-1<s / \varnothing<1)
\end{array}\right.
\end{aligned}
$$

Based on above discussion, the control law for a robot manipulator is written as [10-24]:

$$
\boldsymbol{U}=\boldsymbol{U}_{e q}+\boldsymbol{U}_{\boldsymbol{r}}
$$

Where, the model-based component $\boldsymbol{U}_{\boldsymbol{e q}}$ is the nominal dynamics of systems and $\boldsymbol{U}_{\boldsymbol{e q}}$ can be calculate as follows:

$$
U_{e q}=\left[D^{-1}(f+C+G)+\dot{S}\right] D
$$

and $\boldsymbol{U}_{\text {sat }}$ is computed as;

$$
U_{\text {sat }}=K \cdot \operatorname{sat}(S / \varnothing)
$$

The control output can be written as;

$$
\begin{aligned}
& U=U_{e q}+K \cdot \operatorname{sat}(S / \varnothing) \\
& = \begin{cases}U_{e q}+K \cdot \operatorname{sgn}(S) & ,|S| \geq \varnothing \\
U_{e q}+K \cdot S / \varnothing & ,|S|<\varnothing\end{cases}
\end{aligned}
$$

Second step is focused on design fuzzy estimation variable structure based on Lyapunov formulation. The firs type of fuzzy systems is given by

$$
f(x)=\sum_{l=1}^{M} \theta^{l} \mathcal{E}^{l}(x)=\theta^{T} \mathcal{E}(x)
$$


Where

$\theta=\left(\theta^{1}, \ldots, \theta^{M}\right)^{T}, \varepsilon(x)=$

$\left(\mathcal{E}^{1}(x), \ldots, \mathcal{E}^{M}(x)\right)^{T}$, and $\mathcal{E}^{l}(x)=$

$: \prod_{i=1}^{n} \frac{\mu_{A_{i}^{l}}\left(x_{i}\right)}{m} \sum_{l=1}^{M}\left(\prod_{i=1}^{n} \mu_{A_{i}^{l}}\left(x_{i}\right)\right) . \quad \theta^{1}, \ldots, \theta^{M} \quad$ are adjustable parameters in (58). $\mu_{A_{1}^{1}}\left(x_{1}\right), \ldots, \mu_{A_{n}^{m}}\left(x_{n}\right)$ are given membership functions whose parameters will not change over time.

The second type of fuzzy systems is given by

$$
=\frac{\sum_{l=1}^{M} \theta^{l}\left[\prod_{i=1}^{n} \exp \left(-\left(\frac{x_{i}-\alpha_{i}^{l}}{\delta_{i}^{l}}\right)^{2}\right)\right]}{\sum_{l=1}^{M}\left[\prod_{i=1}^{n} \exp \left(-\left(\frac{x_{i}-\alpha_{i}^{l}}{\delta_{i}^{l}}\right)^{2}\right)\right]}
$$

Where $\theta^{l}, \alpha_{i}^{l}$ and $\delta_{i}^{l}$ are all adjustable parameters. From the universal approximation theorem, we know that we can find a fuzzy system to estimate any continuous function. For the first type of fuzzy systems, we can only adjust $\theta^{l}$ in (58). We define $f^{\wedge}(x \mid \theta)$ as the approximator of the real function $f(x)$.

$$
f^{\wedge}(x \mid \theta)=\theta^{T} \varepsilon(x)
$$

We define $\theta^{*}$ as the values for the minimum error:

$$
\theta^{*}=\arg \min _{\theta \in \Omega}\left[\sup _{x \in U}\left|f^{\wedge}(x \mid \theta)-g(x)\right|\right]
$$

Where $\Omega$ is a constraint set for $\theta$. For specific $x, \sup _{x \in U}\left|f^{\wedge}\left(x \mid \theta^{*}\right)-f(x)\right| \quad$ is the minimum approximation error we can get.

We used the first type of fuzzy systems (59) to estimate the nonlinear system (48) the fuzzy formulation can be write as below;

$$
\begin{aligned}
f(x \mid \theta) & =\theta^{T} \varepsilon(x) \\
& =\frac{\sum_{l=1}^{n} \theta^{l}\left[\mu_{A^{l}}(x)\right]}{\sum_{l=1}^{n}\left[\mu_{A^{l}}(x)\right]}
\end{aligned}
$$

Where $\theta^{1}, \ldots, \theta^{n}$ are adjusted by an adaptation law. The adaptation law is designed to minimize the parameter errors of $\theta-\theta^{*}$. A fuzzy system is designed to compensate the uncertainties of the nonlinear system. The control input is given by

$$
\tau=M^{\wedge} \ddot{q}_{r}+C_{1}^{\wedge} \dot{q}_{r}+G^{\wedge}-F^{\wedge}(s)-F_{c p}(s)
$$

Where $F^{\wedge}(s)=\left[f_{1}^{\wedge}\left(s_{1}\right), \ldots, f_{m}^{\wedge}\left(s_{m}\right)\right]^{T}$ and $F_{c p}(S)=$ $\left[F_{c p 1}\left(s_{1}\right), \ldots, F_{c p_{m}}\left(s_{m}\right)\right]^{T}$. We define $F=\Delta M \ddot{q}_{r}+$ $\Delta C_{1} \dot{q}_{r}+\Delta G \quad$ where $F=\left[f_{1}, \ldots, f_{m}\right]^{T}, \Delta M=M^{\wedge}-$ $M, \Delta C_{1}=C_{1}^{\wedge}-C_{1}$ and $\Delta G_{1}=G^{\wedge}-G$.
From Universal Approximation Theorem in (61), there exists an optimal fuzzy controller $f^{\wedge *}\left(s_{j}\right)$ such that:

$$
\boldsymbol{f}_{j}=\boldsymbol{f}_{j}^{\wedge *}(\boldsymbol{e}, \dot{e})+\Delta_{j}
$$

Where $\Delta_{j}$ is the minimum approximation error.

The fuzzy if-then rules are given by fuzzy rule base. In (62), we assume $\sum_{L=1}^{M} \mu_{A_{j}^{L}}(e, \dot{e})=1$ and $\varepsilon_{j}^{L}(e, \dot{e})$ becomes

$$
\varepsilon_{j}^{L}\left(s_{j}\right)=\frac{\mu_{A_{j}^{L}}(e, \dot{e})}{\sum_{L=1}^{M}\left[\mu_{A_{j}^{L}}(e, \dot{e})\right]}=\mu_{A_{j}^{L}}(e, \dot{e})
$$

Where we define $\varphi_{j}^{L}=\mu_{A_{j}^{L}}(e, \dot{e})$. The membership function $\mu_{A_{j}^{L}}(e, \dot{e})$ is a Gaussian membership function represented by

$$
\mu_{A_{j}^{L}}\left(s_{j}\right)=\exp \left[-\left(\sigma_{j}^{l}\left((e, \dot{e})-\alpha_{j}^{l}\right)\right)^{2}\right]
$$

Then the fuzzy estimator $f^{\wedge}(e, \dot{e})$ is given as

$$
\boldsymbol{f}_{j}^{\wedge}(e, \dot{e})=\theta_{j}^{T} \varphi_{j}
$$

where $\theta_{j}=\left[\theta_{j}^{1}, \ldots, \theta_{j}^{M}\right]^{T}, \varphi_{j}=\left[\varphi_{j}^{1}, \varphi_{j}^{2}, \ldots, \varphi_{j}^{M}\right]^{T}$. We define $\tilde{f}_{j}$ such that

$$
\begin{aligned}
\tilde{f}_{j} & =\boldsymbol{f}_{j}-\boldsymbol{f}_{j}^{\wedge}(\boldsymbol{e}, \dot{e}) \\
& =\boldsymbol{f}_{j}^{\wedge *}(e, \dot{e})-\boldsymbol{f}_{j}^{\wedge}(e, \dot{e})+\Delta_{j} \\
& =\theta_{j}^{* T} \varphi_{j}^{*}-\boldsymbol{\theta}_{j}^{T} \varphi_{j}+\Delta_{j}
\end{aligned}
$$

where $\theta_{j}^{*}$ and $\varphi_{j}^{*}$ are the optimal values based on Universal Approximation Theorem in (61). We define $\tilde{\theta}_{j}=\theta_{j}^{*}-\theta_{j}, \tilde{\varphi}_{j}=\varphi_{j}^{*}-\varphi_{j}$ is rewritten as

$$
\begin{array}{r}
\tilde{\boldsymbol{f}}_{j}=\left(\boldsymbol{\theta}_{j}+\widetilde{\boldsymbol{\theta}}_{j}\right)^{T}\left(\boldsymbol{\varphi}_{j}+\widetilde{\boldsymbol{\varphi}}_{j}\right)-\boldsymbol{\theta}_{j}^{T} \boldsymbol{\varphi}_{j}+\Delta_{j} \\
=\boldsymbol{\theta}_{j}^{T} \widetilde{\boldsymbol{\varphi}}_{j}+\widetilde{\boldsymbol{\theta}}_{j}^{T} \boldsymbol{\varphi}_{j}+\widetilde{\boldsymbol{\theta}}_{j}^{T} \widetilde{\boldsymbol{\varphi}}_{j}+\Delta_{j}
\end{array}
$$

We take Taylor series expansion of $\varphi_{j}$ around two vectors $\alpha_{j}$ and $\sigma_{j}$ where $\alpha_{j}=\left[\alpha_{j}^{1}, \ldots, \alpha_{j}^{M}\right]^{T}$ and $\alpha_{j}=\left[\sigma_{j}^{1}, \ldots, \sigma_{j}^{M}\right]^{T}\left(\alpha_{j}^{l}\right.$ and $\sigma_{j}^{l}$ are defined in (66)):

$$
\varphi_{j}^{*}=\varphi_{j}+\frac{\partial \varphi_{j}}{\partial \alpha_{j}} \widetilde{\alpha}_{j}+\frac{\partial \varphi_{j}}{\partial \alpha_{j}} \widetilde{\sigma}_{j}+\text { h.o.t. }
$$

where $\tilde{\alpha}_{j}=\alpha_{j}^{*}-\alpha_{j}, \tilde{\varphi}_{j}=\varphi_{j}^{*}-\varphi_{j}$ and h.o.t. denotes the higher order terms. We rewrite (70) as

$$
\begin{aligned}
\widetilde{\varphi}_{j} & =\frac{\partial \varphi_{j}}{\partial \alpha_{j}} \widetilde{\alpha}_{j}+\frac{\partial \varphi_{j}}{\partial \alpha_{j}} \widetilde{\sigma}_{j}+\text { h.o.t. } \\
& =B_{j} \widetilde{\alpha}_{j}+C_{j} \widetilde{\sigma}_{j}+\text { h.o.t. }
\end{aligned}
$$


where

$$
\begin{aligned}
B_{j} & =\left[\begin{array}{cccc}
\frac{\partial \varphi_{j}^{1}}{\partial \alpha_{j}^{1}} & \frac{\partial \varphi_{j}^{2}}{\partial \alpha_{j}^{1}} & \cdots & \frac{\partial \varphi_{j}^{M}}{\partial \alpha_{j}^{1}} \\
\frac{\partial \varphi_{j}^{1}}{\partial \alpha_{j}^{2}} & \frac{\partial \varphi_{j}^{2}}{\partial \alpha_{j}^{2}} & \cdots & \frac{\partial \varphi_{j}^{M}}{\partial \alpha_{j}^{2}} \\
\vdots & & & \\
\frac{\partial \varphi_{j}^{1}}{\partial \alpha_{j}^{M}} & \frac{\partial \varphi_{j}^{2}}{\partial \alpha_{j}^{M}} & \cdots & \frac{\partial \varphi_{j}^{M}}{\partial \alpha_{j}^{M}}
\end{array}\right], \\
C_{j} & =\left[\begin{array}{cccc}
\frac{\partial \varphi_{j}^{1}}{\partial \alpha_{j}^{1}} & \frac{\partial \varphi_{j}^{2}}{\partial \alpha_{j}^{1}} & \cdots & \frac{\partial \varphi_{j}^{M}}{\partial \alpha_{j}^{1}} \\
\frac{\partial \varphi_{j}^{1}}{\partial \alpha_{j}^{2}} & \frac{\partial \varphi_{j}^{2}}{\partial \alpha_{j}^{2}} & \cdots & \frac{\partial \varphi_{j}^{M}}{\partial \alpha_{j}^{2}} \\
\vdots & & & \\
\frac{\partial \varphi_{j}^{1}}{\partial \alpha_{j}^{M}} & \frac{\partial \varphi_{j}^{2}}{\partial \alpha_{j}^{M}} & \cdots & \frac{\partial \varphi_{j}^{M}}{\partial \alpha_{j}^{M}}
\end{array}\right]
\end{aligned}
$$

We substitute (71) into (69):

$$
\begin{aligned}
& \widetilde{\boldsymbol{f}}_{j}=\boldsymbol{\theta}_{j}^{T}\left(\boldsymbol{B}_{j} \widetilde{\boldsymbol{\alpha}}_{j}+\boldsymbol{C}_{j} \widetilde{\boldsymbol{\sigma}}_{j}+\text { h. o.t. }\right)+\widetilde{\boldsymbol{\theta}}_{j}^{T} \boldsymbol{\varphi}_{j}+ \\
& \widetilde{\boldsymbol{\theta}}_{j}^{T} \widetilde{\boldsymbol{\varphi}}_{j}+\Delta_{j} \\
& \quad=\boldsymbol{\theta}_{j}^{T} \boldsymbol{B}_{j} \widetilde{\boldsymbol{\alpha}}_{j}+\boldsymbol{\theta}_{j}^{T} C_{j} \widetilde{\boldsymbol{\sigma}}_{j}+\widetilde{\boldsymbol{\theta}}_{j}^{T} \boldsymbol{\varphi}_{j}+ \\
& \boldsymbol{\theta}_{j}^{T} \boldsymbol{h} . \boldsymbol{o} \boldsymbol{t} .+\widetilde{\boldsymbol{\theta}}_{j}^{T} \widetilde{\varphi}_{j}+\Delta_{j} \\
& \quad=\boldsymbol{\theta}_{j}^{T} \boldsymbol{B}_{j} \widetilde{\boldsymbol{\alpha}}_{j}+\boldsymbol{\theta}_{j}^{T} C_{j} \widetilde{\boldsymbol{\sigma}}_{j}+\widetilde{\boldsymbol{\theta}}_{j}^{T} \boldsymbol{\varphi}_{j}+\varepsilon_{j}
\end{aligned}
$$

where $\varepsilon_{j}=\theta_{j}^{T}$ h.o.t. $+\tilde{\theta}_{j}^{T} \tilde{\varphi}_{j}+\Delta_{j}$ is assumed to be bounded by $\left|\varepsilon_{j}\right| \leq E_{j}$. $E_{j}$ is a constant and the value of $E_{j}$ uncertain to the designer. We define $E^{*}$ as the real value and the estimation error is given by

$$
\widetilde{E}_{j}=E_{j}^{*}-E_{j}
$$

Third step is focused on design fuzzy (antecedent and consequent) adaptive fuzzy estimation sliding mode based on Lyapunov formulation. We produce an adaptation law to online tune the following parameters: $\theta_{j}$ in (64), $\sigma_{j}^{l}, \alpha_{j}^{l}$ in (66) and the bound $E_{j}$ in (74). The adaptation laws are expressed as

$$
\begin{aligned}
& \dot{\theta}_{j}=\eta_{j 2} s_{j} \varphi_{j} \\
& \dot{\alpha}_{j}=\eta_{j 3} s_{j} B_{j}^{T} \theta_{j} \\
& \dot{\sigma}_{j}=\eta_{j 4} s_{j} C_{j}^{T} \theta_{j} \\
& f_{c p j}\left(s_{j}\right)=E_{j} \operatorname{sgn}\left(s_{j}\right) \\
& \dot{E}_{j}=\eta_{j 1}\left|s_{j}\right|
\end{aligned}
$$

where $\boldsymbol{\eta}_{\boldsymbol{j} \mathbf{1}}, \boldsymbol{\eta}_{\boldsymbol{j} \mathbf{2}}, \boldsymbol{\eta}_{\boldsymbol{j} \mathbf{3}}$ and $\boldsymbol{\eta}_{\boldsymbol{j} \mathbf{4}}$ are positive constants; $\boldsymbol{\theta}_{\boldsymbol{j}}=\left[\theta_{j}^{1}, \theta_{j}^{2}, \ldots, \theta_{j}^{M}\right]^{T} \quad, \quad \boldsymbol{\alpha}_{\boldsymbol{j}}=\left[\alpha_{j}^{1}, \alpha_{j}^{2}, \ldots, \alpha_{j}^{M}\right]^{T}$, $\boldsymbol{\sigma}_{j}=\left[\sigma_{j}^{1}, \sigma_{j}^{2}, \ldots, \sigma_{j}^{M}\right]^{T} ; B_{j}, C_{j}$ are given in (72); $\boldsymbol{f}_{\boldsymbol{c p} \boldsymbol{j}}\left(\boldsymbol{s}_{\boldsymbol{j}}\right)$ is the compensation term defined in (63).

If the following Lyapunov function candidate defined by:

$$
V=\frac{1}{2} s^{T} M s+\frac{1}{2} \sum_{j=1}^{m}\left(\frac{\widetilde{E}_{j}^{2}}{\eta_{j 1}}+\frac{\widetilde{\theta}_{j}^{T} \widetilde{\theta}}{\eta_{j 2}}+\frac{\widetilde{\alpha}_{j}^{T} \widetilde{\alpha}}{\eta_{j 3}}+\frac{\widetilde{\sigma}_{j}^{T} \widetilde{\sigma}}{\eta_{j 4}}\right)
$$

The derivative of $V$ is defined by:

$$
\begin{aligned}
& \dot{V}=s^{T} M \dot{s}+\frac{1}{2} s^{T} \dot{M} s+\sum_{j=1}^{m}\left(\frac{\widetilde{E}_{j} \tilde{E}_{j}}{\eta_{j 1}}+\frac{\tilde{\theta}_{j}^{T} \dot{\theta}}{\eta_{j 2}}+\right. \\
& \left.\frac{\widetilde{\alpha}_{j}^{T} \dot{\tilde{\alpha}}}{\eta_{j 3}}+\frac{\widetilde{\sigma}_{j}^{T} \tilde{\sigma}}{\eta_{j 4}}\right)
\end{aligned}
$$

where $\widetilde{\boldsymbol{E}}_{\boldsymbol{j}}=\boldsymbol{E}_{j}^{*}-\boldsymbol{E}_{j}, \widetilde{\boldsymbol{\theta}}_{\boldsymbol{j}}=\boldsymbol{\theta}_{j}^{*}-\boldsymbol{\theta}_{j}, \widetilde{\boldsymbol{\alpha}}_{\boldsymbol{j}}=\boldsymbol{\alpha}_{j}^{*}-$ $\alpha_{j}, \quad \widetilde{\sigma}_{j}=\sigma_{j}^{*}-\sigma_{j}$. from robot manipulator formulation and (1):

$$
\begin{aligned}
& D(q) \ddot{q}+f_{1}(q, \dot{q}) \dot{q}+G(q)=D^{\wedge} \ddot{q}_{r}+ \\
& f_{1}^{\wedge} \dot{q}_{r}+G^{\wedge}-F^{\wedge}(s)-F_{c p}(s)
\end{aligned}
$$

Since $\dot{D}-2 C_{1}$ is a skew-symmetric matrix, we can get $s^{T} D \dot{s}+\frac{1}{2} s^{T} \dot{D} s=s^{T}\left(D \dot{s}+C_{1} s\right)$. From

$$
\begin{gathered}
\dot{\boldsymbol{q}}_{r}=\dot{\boldsymbol{q}}-\boldsymbol{s}=\dot{\boldsymbol{q}}_{d}-\lambda \boldsymbol{e} \text { and } \ddot{q}_{r}=\ddot{\boldsymbol{q}}-\dot{s}=\ddot{q}_{d}-\lambda \dot{e} \\
M \dot{s}+C_{1} s=F-F^{\wedge}(s)-F_{c p}(s)
\end{gathered}
$$

where $=\Delta M \ddot{q}_{r}+\Delta C_{1} \dot{q}_{r}+\Delta G \quad, \quad \Delta M=M^{\wedge}-$ $M, \Delta C_{1}=C_{1}^{\wedge}-C_{1}$ and $\Delta G_{1}=G^{\wedge}-G$. Then $\dot{V}$ becomes

$$
\begin{aligned}
& \dot{V}=s^{T}\left(M \dot{s}+C_{1} s\right)+\sum_{j=1}^{m}\left(\frac{\tilde{E}_{j} \dot{\tilde{E}}_{j}}{\eta_{j 1}}+\frac{\widetilde{\theta}_{j}^{T} \dot{\tilde{\theta}}}{\eta_{j 2}}+\right. \\
& \left.\frac{\widetilde{\alpha}_{j}^{T} \dot{\tilde{\alpha}}}{\eta_{j 3}}+\frac{\widetilde{\sigma}_{j}^{T} \dot{\widetilde{\sigma}}}{\eta_{j 4}}\right) \\
& =s^{T}\left(F-F^{\wedge}(s)-F_{c p}(s)\right)+ \\
& \sum_{j=1}^{m}\left(\frac{\widetilde{E}_{j} \tilde{\tilde{E}}_{j}}{\eta_{j 1}}+\frac{\widetilde{\theta}_{j}^{T} \dot{\tilde{\theta}}}{\eta_{j 2}}+\frac{\widetilde{\alpha}_{j}^{T} \dot{\tilde{\alpha}}}{\eta_{j 3}}+\frac{\widetilde{\sigma}_{j}^{T} \tilde{\tilde{\sigma}}}{\eta_{j 4}}\right) \\
& =\sum_{j=1}^{m} s_{j}\left(f_{j}-f^{\wedge}{ }_{j}\left(s_{j}\right)-f_{c p j}\right)+ \\
& \sum_{j=1}^{m}\left(\frac{\tilde{E}_{j} \dot{\tilde{E}}_{j}}{\eta_{j 1}}+\frac{\widetilde{\theta}_{j}^{T} \dot{\tilde{\theta}}_{j 2}}{\eta_{j 2}}+\frac{\widetilde{\alpha}_{j}^{T} \dot{\tilde{\alpha}}}{\eta_{j 3}}+\frac{\widetilde{\sigma}_{j}^{T} \dot{\tilde{\sigma}}}{\eta_{j 4}}\right) \\
& =\sum_{j=1}^{m} s_{j}\left(\theta_{j}^{T} B_{j} \tilde{\alpha}_{j}+\theta_{j}^{T} C_{j} \tilde{\sigma}_{j}+\tilde{\theta}_{j}^{T} \varphi_{j}+\varepsilon_{j}-\right. \\
& \left.f_{c p j}\right)-\sum_{j=1}^{m}\left(\frac{\tilde{E}_{j} \dot{E}_{j}}{\eta_{j 1}}+\frac{\widetilde{\theta}_{j}^{T} \dot{\tilde{\theta}}}{\eta_{j 2}}+\frac{\widetilde{\alpha}_{j}^{T} \dot{\tilde{\alpha}}}{\eta_{j 3}}+\frac{\widetilde{\sigma}_{j}^{T} \dot{\tilde{\sigma}}}{\eta_{j 4}}\right) \\
& =\sum_{j=\mathbf{1}}^{\boldsymbol{m}}\left[\tilde{\theta}_{j}^{T}\left(s_{j} \varphi_{j}-\frac{\dot{\theta}_{j}}{\eta_{j 2}}\right)+\tilde{\alpha}_{j}^{T}\left(s_{j} B_{j}^{T} \theta_{j}-\right.\right. \\
& \left.\left.\frac{\dot{\alpha}_{j}}{\eta_{j 3}}\right)+\tilde{\sigma}_{j}^{T}\left(s_{j} C_{j}^{T} \theta_{j}-\frac{\dot{\sigma}_{j}}{\eta_{j 4}}\right)\right]+\sum_{j=\mathbf{1}}^{m}\left(s_{j} \varepsilon_{j}-\right. \\
& \left.s_{j} f_{c p j} \frac{\widetilde{\boldsymbol{E}}_{\boldsymbol{j}} \widetilde{\boldsymbol{E}}_{\boldsymbol{j}}}{\eta_{\boldsymbol{j} 1}}\right)
\end{aligned}
$$

We substitute the adaption law (75)-(79) in to (84): 


$$
\begin{aligned}
\dot{V} & =\sum_{j=1}^{m}\left[s_{j} \varepsilon_{j}-s_{j} E_{j} \operatorname{sgn}\left(s_{j}\right)-\tilde{E}_{j}\left|s_{j}\right|\right] \\
& =\sum_{j=1}^{m}\left[s_{j} \varepsilon_{j}-s_{j} E_{j} \operatorname{sgn}\left(s_{j}\right)-\left(E_{j}^{*}\right.\right. \\
& =\sum_{j=1}^{m}\left[s_{j} \varepsilon_{j}-E_{j} \operatorname{sgn}\left(s_{j}\right)\right] \\
& =\sum_{j=1}^{m}\left[\left|s_{j}\right|\left|\varepsilon_{j}\right|-E_{j}^{*}\left|s_{j}\right|\right] \\
& =\sum_{j=1}^{m}\left[\left|s_{j}\right|\left(\left|\varepsilon_{j}\right|-E_{j}^{*}\right)\right] \leq \mathbf{0}
\end{aligned}
$$

where $\dot{\boldsymbol{V}}$ is negative semidefinite. We define $\dot{V}_{j}=\left|s_{j}(t)\right|\left(\left|\varepsilon_{j}\right|-E_{j}^{*}\right)$. From $\dot{V}_{j} \leq 0$, we can get $s_{j}(t)$ is bounded. We assume $\left|s_{j}(t)\right| \leq \eta_{s}$ and rewrite $\left|s_{j}(t)\right|\left(E_{j}^{*}-\left|\varepsilon_{j}\right|\right) \leq-\dot{V}_{j}$ as

$$
\begin{aligned}
& s_{j}(t) \leq \frac{1}{E_{j}^{*}}\left|s_{j}(t)\right|\left|\varepsilon_{j}\right|-\frac{1}{E_{j}^{*}} \dot{V}_{j} \leq \frac{\eta_{s}}{E_{j}^{*}}\left|\varepsilon_{j}\right|- \\
& \frac{1}{E_{j}^{*}} \dot{V}_{j}
\end{aligned}
$$

Then we take the integral on both sides of (86):

$$
\begin{aligned}
& \int_{0}^{t}\left|s_{j}(v)\right| d v \leq \frac{\eta_{s}}{E_{j}^{*}} \int_{0}^{t}\left|\varepsilon_{j}\right| d v+\frac{1}{E_{j}^{*}}\left(V_{j}(0)-\right. \\
& \left.V_{j}(t)\right) \leq \frac{\eta_{s}}{E_{j}^{*}} \int_{0}^{t}\left|\varepsilon_{j}\right| d v+\frac{1}{E_{j}^{*}}\left(\left|V_{j}(0)\right|-\right. \\
& \left.\left|V_{j}(t)\right|\right)
\end{aligned}
$$

If $\varepsilon_{j} \in L_{1}$, we can get $s_{j} \in L_{1}$ from(87). Since we can prove $\dot{s}_{j}$ is bounded (see proof in [15]), we have $\dot{s}_{j} \in L_{\infty}$. We introduce the following Barbalat 's Lemma[16].

Lemma: let $\emptyset: R \rightarrow R$ be a uniformly continues function on $[0, \infty)$. Suppose that $\lim _{t \rightarrow \infty} \int_{0}^{t} \emptyset(\tau) d \tau$ exists and is finite. Then,

$$
\lim _{t \rightarrow \infty} \emptyset(t)=0
$$

Therefore, by using Barbalat 's Lemma, we can get $\lim _{t \rightarrow \infty} s_{j}(t)=0$ and $\lim _{t \rightarrow \infty} e_{j}(t)=0$.

\section{Results}

This methodology can online adjust both the premise and the consequent parts of the fuzzy rules. In this method we choose $\widehat{M}, \widehat{B}$ and $\widehat{C}$ for compensation. We define five membership functions for each input variable based on

$$
\mu_{A_{j}^{l}}\left(S_{j}\right)=\exp \left[-\left(\sigma_{j}^{l}\left(S_{j}-\alpha_{j}^{l}\right)\right)^{2}\right]
$$

Sliding mode controller (SMC) and proposed fuzzy (premise and the consequent) adaptive fuzzy estimator sliding mode controller were tested to sinus response trajectory. The simulation was implemented in Matlab/Simulink environment. Link/joint trajectory and disturbance rejection are compared in these controllers. These systems are tested by band limited white noise with a predefined $40 \%$ of relative to the input signal amplitude.

Link/joint Trajectory: Figure 1 shows the link/joint trajectory in SMC and proposed methodology without disturbance for sinus trajectory. (This techniques is applied to first two link of continuum robot manipulator)
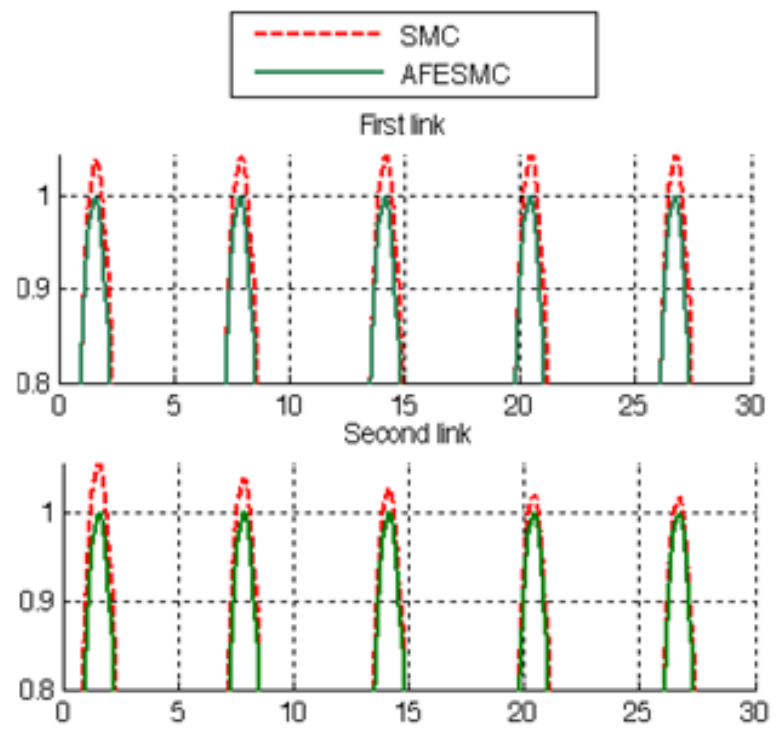

Fig. 1: Proposed method (AFESMC) and SMC trajectory: applied to continuum robot manipulator

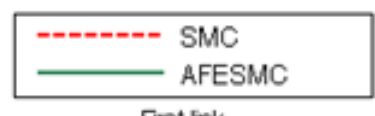

First ink
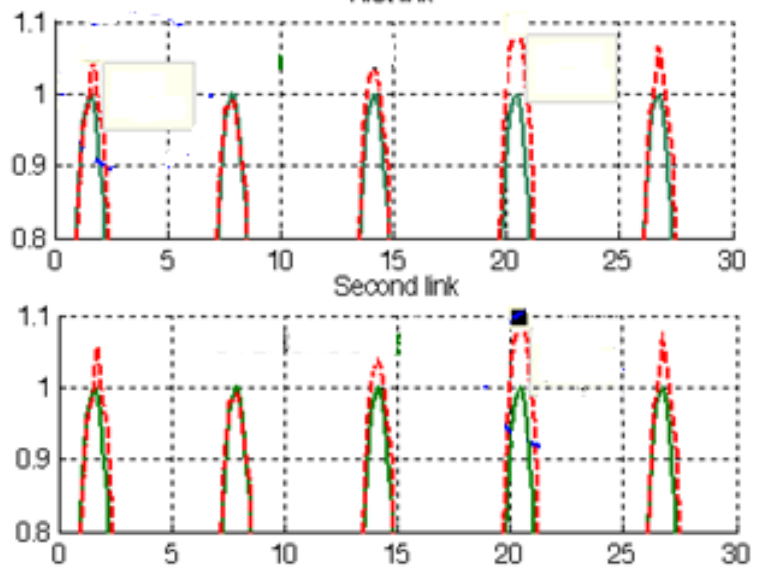

Fig. 2: Proposed controller (AFESMC) and SMC trajectory with external disturbance: applied to robot manipulator

By comparing sinus response, Figure 1, in SMC and proposed controller, the proposed controller's overs hoot (0\%) is lower than SMC's (3\%). 
Disturbance rejection: Figure 2 is indicated the power disturbance removal in SMC and proposed controller. Besides a band limited white noise with predefined of $40 \%$ the power of input signal is applied to the sinus SMC and proposed controller; it found slight oscillations in SMC trajectory responses.

\section{Conclusion}

In this paper, a fuzzy (premise and consequent) adaptive robust control fuzzy estimator sliding mode method is proposed in order to design a high performance robust controller in the presence of structured uncertainties and unstructured uncertainties. The approach improves performance by using the advantages of sliding mode control, fuzzy logic estimation method and adaptive control while the disadvantages attributed to these methods are remedied by each other. This is achieved without increasing the complexities of the overall design and analysis of the controller. The proposed controller attenuates the effort of model uncertainties from both structured uncertainties and unstructured uncertainties. Thus, transient performance and final tracking accuracy is guaranteed by proper design of the controller. The results revealed that adaption of fuzzy rules weights reduce the model uncertainties significantly, and hence farther improvements of the tracking performance can be achieved. This algorithm created a methodology of learning both the premise and the consequence part of fuzzy rules. In this method chattering is eliminated.

\section{Acknowledgment}

The authors would like to thank the anonymous reviewers for their careful reading of this paper and for their helpful comments. This work was supported by the SSP Research and Development Corporation Program of Iran undergrant no. 2012-Persian Gulf-3C.

\section{References}

[1] G. Robinson, and J. Davies, "Continuum robots - a state of the art,"Proc. IEEE International Conference on Robotics and Automation, Detroit, MI, 1999, vol. 4, pp. 2849-2854.

[2] I.D. Walker, D. Dawson, T. Flash, F. Grasso, R. Hanlon, B. Hochner, W.M. Kier, C. Pagano,C.D. Rahn, Q. Zhang, "Continuum Robot Arms Inspired by Cephalopods, Proceedings SPIE Conference on Unmanned Ground Vehicle Technology VII, Orlando, FL, pp 303-314, 2005.

[3] K. Suzumori, S. Iikura, and H. Tanaka, "Development of Flexible Microactuator and it's Applications to Robotic Mechanisms", Proceedings IEEE International Conference on
Robotics and Automation, Sacramento, California, pp. 1622-1627, 1991.

[4] D. Trivedi, C.D. Rahn, W.M. Kier, and I.D. Walker, "Soft Robotics: Biological Inspiration, State of the Art, and Future Research", Applied Bionics and Biomechanics, 5(2), pp. 99-117, 2008.

[5] W. McMahan, M. Pritts, V. Chitrakaran, D. Dienno, M. Grissom, B. Jones, M. Csencsits, C.D. Rahn, D. Dawson, and I.D. Walker, "Field Trials and Testing of "OCTARM" Continuum Robots", Proc. IEEE International Conference on Robotics and Automation, pp. 2336-2341, 2006.

[6] W. McMahan, I.D. Walker, “Octopus-Ins pired Grasp Synergies for Continuum Manipulators", Proc. IEEE International Conference on Robotics and Biomimetics, pp. 945- 950, 2009.

[7] I. Boiko, L. Fridman, A. Pisano and E. Usai, "Analysis of chattering in systems with secondorder sliding modes," IEEE Transactions on Automatic Control, No. 11, vol. 52,pp. 2085-2102, 2007.

[8] J. Wang, A. Rad and P. Chan, "Indirect adaptive fuzzy sliding mode control: Part I: fuzzy switching," Fuzzy Sets and Systems, No. 1, vol. 122,pp. 21-30, 2001.

[9] M. Bazregar, Farzin Piltan, A. Nabaee and M.M. Ebrahimi, "Parallel Soft Computing Control Optimization Algorithm for Uncertainty Dynamic Systems", International Journal of Advanced Science and Technology, 51, 2013.

[10] Farzin Piltan, M.H. Yarmahmoudi, M. Mirzaei, S. Emamzadeh, Z. Hivand, "Design Novel Fuzzy Robust Feedback Linearization Control with Application to Robot Manipulator", International Journal of Intelligent Systems and Applications, 5(5), 2013.

[11] Sh. Tayebi Haghighi, S. Soltani, Farzin Piltan, M. kamgari, S. Zare, "Evaluation Performance of IC Engine: Linear Tunable Gain Computed Torque Controller Vs. Sliding Mode Controller", International Journal of Intelligent Systems and Applications, 5(6), 2013.

[12] Farzin Piltan, A. R. Salehi \& Nasri B Sulaiman,"Design Artificial Robust Control of Second Order System Based on Adaptive Fuzzy Gain Scheduling", World Applied Science Journal (WASJ), 13 (5): 1085-1092, 2011.

[13] Farzin Piltan, N. Sulaiman, Atefeh Gavahian, Samira Soltani \& Samaneh Roosta, "Design Mathematical Tunable Gain PID-Like Sliding Mode Fuzzy Controller with Minimum Rule Base", International Journal of Robotic and Automation, 2 (3): 146-156, 2011.

[14] Farzin Piltan , N. Sulaiman, Zahra Tajpaykar, Payman Ferdosali \& Mehdi Rashidi, "Design 
Artificial Nonlinear Robust Controller Based on CTLC and FSMC with Tunable Gain", International Journal of Robotic and Automation, 2 (3): 205-220, 2011.

[15] Farzin Piltan, Mohammad Mansoorzadeh, Saeed Zare, Fatemeh Shahriarzadeh, Mehdi Akbari, "Artificial tune of fuel ratio: Design a novel siso fuzzy backstepping adaptive variable structure control", International Journal of Electrical and Computer Engineering (IJECE), 3 (2): 183-204, 2013.

[16] Farzin Piltan, M. Bazregar, M. Kamgari, M. Akbari, M. Piran, "Adjust the fuel ratio by high impact chattering free sliding methodology with application to automotive engine", International Journal of Hybrid Information Technology (IJHIT), 6 (1): 13-24, 2013.

[17] Shahnaz Tayebi Haghighi, S. Soltani, Farzin Piltan, M. Kamgari, S. Zare, "Evaluation Performance of IC Engine: linear tunable gain computed torque controller Vs. Sliding mode controller", I. J. Intelligent system and application, 6 (6): 78-88, 2013.

[18] Farzin Piltan, N. Sulaiman, Payman Ferdosali \& Iraj Assadi Talooki, "Design Model Free Fuzzy Sliding Mode Control: Applied to Internal Combustion Engine", International Journal of Engineering, 5 (4):302-312, 2011.

[19] Farzin Piltan, N. Sulaiman, A. Jalali \& F. Danesh Narouei, "Design of Model Free Adaptive Fuzzy Computed Torque Controller: Applied to Nonlinear Second Order System", International Journal of Robotics and Automation, 2 (4):245-257, 2011.

[20] A. Jalali, Farzin Piltan, M. Keshtgar, M. Jalali, "Colonial Competitive Optimization Sliding Mode Controller with Application to Robot Manipulator", International Journal of Intelligent Systems and Applications, 5(7), 2013.

[21] Farzin Piltan, Amin Jalali, N. Sulaiman, Atefeh Gavahian \& Sobhan Siamak, "Novel Artificial Control of Nonlinear Uncertain System: Design a Novel Modified PSO SISO Lyapunov Based Fuzzy Sliding Mode Algorithm", International Journal of Robotics and Automation, 2 (5): 298 316, 2011.

[22] Farzin Piltan, N. Sulaiman, Iraj Asadi Talooki \& Payman Ferdosali, "Control of IC Engine: Design a Novel MIMO Fuzzy Backstepping Adaptive Based Fuzzy Estimator Variable Structure Control", International Journal of Robotics and Automation, 2 (5):360-380, 2011.

[23] Farzin Piltan, N. Sulaiman, S.Soltani, M. H. Marhaban \& R. Ramli, "An Adaptive Sliding Surface Slope Adjustment in PD Sliding Mode Fuzzy Control For Robot Manipulator",
International Journal of Control and Automation, 4 (3): 65-76, 2011.

[24] Farzin Piltan, N. Sulaiman, Mehdi Rashidi, Zahra Tajpaikar \& Payman Ferdosali, "Design and Implementation of Sliding Mode Algorithm: Applied to Robot Manipulator-A Review", International Journal of Robotics and Automation, 2 (5):265-282, 2011.

[25] Farzin Piltan, N. Sulaiman , Arash Zargari, Mohammad Keshavarz \& Ali Badri, "Design PIDLike Fuzzy Controller with Minimum Rule Base and Mathematical Proposed On-line Tunable Gain: Applied to Robot Manipulator", International Journal of Artificial Intelligence and Expert System, 2 (4):184-195, 2011.

[26] Farzin Piltan, SH. Tayebi HAGHIGHI, N. Sulaiman, Iman Nazari \& Sobhan Siamak, "Artificial Control of PUMA Robot Manipulator: A-Review of Fuzzy Inference Engine and Application to Classical Controller", International Journal of Robotics and Automation, 2 (5):401-425, 2011.

[27] A. Salehi, Farzin Piltan, M. Mousavi, A. Khajeh, M. R. Rashidian, "Intelligent Robust Feed-forward Fuzzy Feedback Linearization Estimation of PID Control with Application to Continuum Robot", International Journal of Information Engineering and Electronic Business, 5(1), 2013.

[28] Farzin Piltan, N. Sulaiman \& I.AsadiTalooki, "Evolutionary Design on-line Sliding Fuzzy Gain Scheduling Sliding Mode Algorithm: Applied to Internal Co mbustion Engine", International Journal of Engineering Science and Technology, 3 (10):7301-7308, 2011.

[29] Farzin Piltan, Nasri B Su laiman, Iraj Asadi Talooki \& Payman Ferdosali, "Designing On-Line Tunable Gain Fuzzy Sliding Mode Controller Using Sliding Mode Fuzzy Algorithm: Applied to Internal Combustion Engine" World Applied Science Journal (W ASJ), 15 (3): 422-428, 2011.

[30] Farzin Piltan, M.J. Rafaati, F. Khazaeni, A. Hosainpour, S. Soltani, "A Design High Impact Lyapunov Fuzzy PD-Plus-Gravity Controller with Application to Rigid Manipulator", International Journal of Information Engineering and Electronic Business, 5(1), 2013.

[31] A. Jalali, Farzin Piltan, A. Gavahian, M. Jalali, M. Adibi, "Model-Free Adaptive Fuzzy Sliding Mode Controller Optimized by Particle Swarm for Robot man ipulator", International Journal of Information Engineering and Electronic Business, 5(1), 2013.

[32] Farzin Piltan, N. Sulaiman, Payman Ferdosali, Mehdi Rashidi \& Zahra Tajpeikar, "Adaptive MIMO Fuzzy Compensate Fuzzy Sliding Mode Algorithm: Applied to Second Order Nonlinear 
System", International Journal of Engineering, 5 (5): 380-398, 2011.

[33] Farzin Piltan, N. Sulaiman, Hajar Nasiri, Sadeq Allahdadi \& Mohammad A. Bairami, "Novel Robot Manipulator Adaptive Artificial Control: Design a Novel SISO Adaptive Fuzzy Sliding Algorithm Inverse Dynamic Like Method", International Journal of Engineering, 5 (5): 399418, 2011.

[34] Farzin Piltan, N. Sulaiman, Sadeq Allahdadi, Mohammadali Dialame \& Abbas Zare, "Position Control of Robot Manipulator: Design a Novel SISO Adaptive Sliding Mode Fuzzy PD Fuzzy Sliding Mode Control", International Journal of Artificial Intelligence and Expert System, 2 (5):208-228, 2011.

[35] M. M. Ebrahimi, Farzin Piltan, M. Bazregar and A.R. Nabaee "Intelligent Robust Fuzzy-Parallel Optimization Control of a Continuum Robot Manipulator", International Journal of Control and Automation, 6(3), 2013.

[36] Farzin Piltan, M.A. Bairami, F. Aghayari, M.R. Rashidian, "Stable Fuzzy PD Control with Parallel Sliding Mode Compensation with Application to Rigid Manipulator", International Journal of Information Technology and Computer Science, 5(7), 2013.

[37] Farzin Piltan, N. Sulaiman, Samaneh Roosta, Atefeh Gavahian \& Samira Soltani, "Evolutionary Design of Backstepping Artificial Sliding Mode Based Position Algorithm: Applied to Robot Manipulator", International Journal of Engineering, 5 (5):419-434, 2011.

[38] Farzin Piltan, N. Sulaiman, Amin Jalali, Sobhan Siamak \& Iman Nazari, "Control of Robot Manipulator: Design a Novel Tuning MIMO Fuzzy Backstepping Adaptive Based Fuzzy Estimator Variable Structure Control”, International Journal of Control and Automation, 4 (4):91-110, 2011.

[39] Farzin Piltan, N. Sulaiman, Atefeh Gavahian, Samaneh Roosta \& Samira Soltani, "On line Tuning Premise and Consequence FIS: Design Fuzzy Adaptive Fuzzy Sliding Mode Controller Based on Lyaponuv Theory", International Journal of Robotics and Automation, 2 (5):381-400, 2011.

[40] Farzin Piltan, N. Sulaiman, Samira Soltani, Samaneh Roosta \& Atefeh Gavahian, "Artificial Chattering Free on-line Fuzzy Sliding Mode Algorith m for Uncertain System: Applied in Robot Manipulator", International Journal of Engineering, 5 (5):360-379, 2011.

[41] Farzin Piltan, F. ShahryarZadeh ,M. Mansoorzadeh ,M. kamgari, S. Zare, "Robust Fuzzy PD Method with Parallel Computed Fuel Ratio Estimation Applied to Automotive Engine
"International Journal of Intelligent Systems and Applications, 5(8), 2013.

[42] Farzin Piltan, Sadeq Allahdadi, Mohammad A.Bairami \& Hajar Nasiri, "Design Auto Adjust Sliding Surface Slope: Applied to Robot Manipulator", International Journal of Robotics and Automation, 3 (1):27-44, 2011.

[43] Farzin Piltan, Mohammadali Dialame, Abbas Zare \& Ali Badri, "Design Novel Lookup Table Changed Auto Tuning FSMC:Applied to Robot Manipulator", International Journal of Engineering, 6 (1):25-41, 2012.

[44] Farzin Piltan, M. Keshavarz, A. Badri \& A. Zargari, "Design Novel Nonlinear Controller Applied to RobotManipulator: Design New Feedback Linearization Fuzzy Controller with Minimum Rule Base Tuning Method", International Journal of Robotics and Automation, 3 (1):1-12, 2012.

[45] Farzin Piltan, Mohammad A.Bairami, Farid Aghayari \& Sadeq Allahdadi, "Design Adaptive Artificial Inverse Dynamic Controller: Design Sliding Mode Fuzzy Adaptive New Inverse Dynamic Fuzzy Controller", International Journal of Robotics and Automation, (1):13-26, 2012.

[46] Farzin Piltan, Sadeq Allahdadi, Mohammad A.Bairami \& Hajar Nasiri, "Design Auto Adjust Sliding Surface Slope: Applied to Robot Manipulator", International Journal of Robotics and Automation, 3 (1):27-44, 2012.

[47] Farzin Piltan, F. Aghayari, M. Rashidian \& M. Shamsodini, "A New Estimate Sliding Mode Fuzzy Controller for RoboticManipulator", International Journal of Robotics and Automation, 3 (1):45-60, 2012

[48] Farzin Piltan, Iman Nazari, Sobhan Siamak, Payman Ferdosali, "Methodology of FPGA-Based Mathematical error-Based Tuning Sliding Mode Controller", International Journal of Control and Automation, 5(1), 89-118, 2012.

[49] Farzin Piltan, Bamdad Boroomand, Arman Jahed \& Hossein Rezaie, "Methodology of Mathematical Error-Based Tuning Sliding Mode Controller", International Journal of Engineering, 6 (2):96-117, 2012.

[50] Farzin Piltan, S. Emamzadeh, Z. Hivand, F. Shahriyari \& Mina Mirazaei. " PUMA-560 Robot Manipulator Position Sliding Mode Control Methods Using MATLAB/SIMULINK and Their Integration into Graduate/Undergraduate Nonlinear Control, Robotics and MATLAB Courses", International Journal of Robotics and Automation, 3(3):106-150, 2012.

[51] Farzin Piltan, A. Hosainpour, E. Mazlomian, M.Shamsodini, M.H Yarmahmoudi. "Online 
Tuning Chattering Free Sliding Mode Fuzzy Control Design: Lyapunov Approach", International Journal of Robotics and Automation, 3(3):77-105, 2012.

[52] Farzin Piltan, J. Meigolinedjad, S. Mehrara, S. Rahmdel. "Evaluation Performance of $2^{\text {nd }}$ Order Nonlinear System: Baseline Control Tunable Gain Sliding Mode Methodology", International Journal of Robotics and Automation, 3(3): 192-211, 2012.

[53] Farzin Piltan, Sajad Rahmdel, Saleh Mehrara, Reza Bayat , "Sliding Mode Methodology Vs. Computed Torque Methodology Using MATLAB/SIMULINK and Their Integration into Graduate Nonlinear Control Courses", International Journal of Engineering, 6(3): 142-177, 2012.

[54] Farzin Piltan, Hossein Rezaie, Bamdad Boroomand, Arman Jahed. "Design Robust Backstepping on-line Tuning Feedback Linearization Control Applied to IC Engine", International Journal of Advance Science and Technology, 11:40-22, 2012.

[55] Farzin Piltan, S. Siamak, M.A. Bairami and I. Nazari. " Gradient Descent Optimal Chattering Free Sliding Mode Fuzzy Control Design: Lyapunov Approach", International Journal of Advanced Science and Technology, 43: 73-90, 2012.

[56] Farzin Piltan, M.R. Rashidian, M. Shamsodini and S. Allahdadi." Effect of Rule Base on the FuzzyBased Tuning Fuzzy Sliding Mode Controller: Applied to $2^{\text {nd }}$ Order Nonlinear System", International Journal of Advanced Science and Technology, 46:39-70, 2012.

[57] Farzin Piltan, A. Jahed, H. Rezaie and B. Boroo mand." Methodology of Robust Linear Online High Speed Tuning for Stable Sliding Mode Controller: Applied to Nonlinear System", International Journal of Control and Automation, 5(3): 217-236, 2012.

[58] Farzin Piltan, R. Bayat, S. Mehara and J. Meigolinedjad. "GDO Artificial IntelligenceBased Switching PID Baseline Feedback Linearization Method: Controlled PUMA Workspace", International Journal of Information Engineering and Electronic Business, 5: 17-26, 2012.

[59] Farzin Piltan, B. Boroomand, A. Jahed and H. Rezaie. "Performance-Based Adaptive Gradient Descent Optimal Coefficient Fuzzy Sliding Mode Methodology", International Journal of Intelligent Systems and Applications, 11: 40-52 2012.

[60] Farzin Piltan, S. Mehrara, R. Bayat and S. Rahmdel. " Design New Control Methodology of Industrial Robot Manipulator: Sliding Mode
Baseline Methodology", International Journal of Hybrid Information Technology, 5(4):41-54, 2012.

[61] Farzin Piltan, Shahnaz Tayebi Haghighi, "Design Gradient Descent Optimal Sliding Mode Control of Continuum Robots", International Journal of Robotics and Automation, 1(4): 175-189, 2012.

[62] Farzin Piltan, A. Nabaee, M.M. Ebrahimi, M. Bazregar, "Design Robust Fuzzy Sliding Mode Control Technique for Robot Manipulator Systems with Modeling Uncertainties", International Journal of Information Technology and Computer Science, 5(8), 2013.

\section{Authors' Profiles}

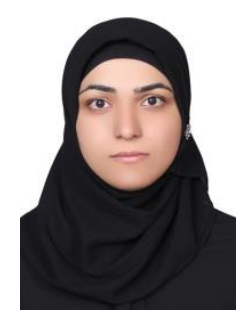

Narges Gholami mozafari is currently working as a co researcher in Control and Robotic Lab at the institute of advance science and technology, SSP Research Center. Her current research interests are in the area of nonlinear control, artificial control systems and robotics.

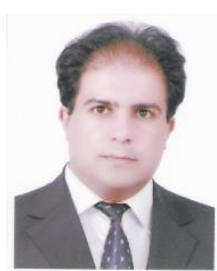

Farzin Piltan was born on 1975, Shiraz, Iran. In 2004 he is jointed as a senior researcher to the Control and Robotic Lab at the institute of advance science and technology, SSP Research Center. In addition to 7 textbooks, Farzin Piltan is the main author of more than 90 scientific papers in refereed journals. He is editorial review board member for 'international journal of control and automation (IJCA), Australia, ISSN: 2005-4297; 'International Journal of Intelligent System and Applications (IJISA)', Hong Kong, ISSN: 2074-9058; 'IAES international journal of robotics and automation, Malaysia, ISSN: 2089-4856; 'International Journal of Reconfigurable and Embedded Systems', Malaysia, ISSN: 2089-4864. His current research interests are nonlinear control, artificial control system and applied to FPGA, robotics and artificial nonlinear control and IC engine modeling and control.

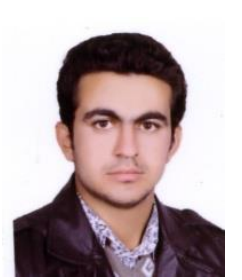

Mohammad Shamsodini is currently working as a co researcher in Control and Robotic Lab at the institute of advance science and technology, SSP Research Center. His current research interests are in the area of nonlinear control, artificial control systems and robotics. 


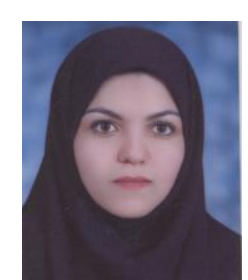

Azita Yazdanpanah is currently working as a co researcher in Control and Robotic Lab at the institute of advance science and technology, SSP Research Center. Her current research interests are in the area of nonlinear control, artificial control systems and robotics.

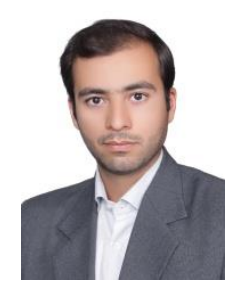

Ali Roshanzamir is currently working as a co researcher in Control and Robotic Lab at the institute of advance science and technology, SSP Research Center. His current research interests are in the area of nonlinear control, artificial control systems and robotics.

How to cite this paper: Narges Gholami Mozafari, Farzin Piltan, Mohammad Shamsodini, Azita Yazdanpanah, Ali Roshanzamir,"On Line Tuning Premise and Consequence FIS Based on Lyaponuv Theory with Application to Continuum Robot", International Journal of Intelligent Systems and Applications(IJISA), vol.6, no.3, pp.96-110, 2014. DOI: 10.5815/ijisa.2014.03.10 